\title{
THE FORMATION OF FJORD THRESHOLDS
}

\author{
By E. M. SHOEMAKER
}

(Department of Mathematics, Simon Fraser University, Burnaby, British Columbia V5A 1S6, Canada)

\begin{abstract}
The erosion rate of bedrock by glacier action is analyzed under conditions of constant-state radial convergent and divergent flow, assuming that the quarrying rate increases with increasing sliding velocity, and assuming a conventional power-function sliding law. Ice is modeled as a non-linear Glen material. Deviatoric stresses are computed but are shown to be negligible compared to the basal shear stress, provided that suitable restraints are placed on the ratio of channel radius of curvature to ice thickness. If the ice is sufficiently thick, radial divergent flow results in erosion rates which decrease in the down-stream direction. This provides an explanation for the formation of the largest class of fjord thresholds which occur at channel widenings. In contrast, increased erosion rates are predicted at narrows which can explain the presence of deep troughs at gradual narrows. It is argued that the presence of pronounced thresholds in abrupt narrows can be explained by low quarryability or locally high roughness which reduces the sliding velocity. The origin of till overlying thresholds is explained as a natural consequence of a threshold being a position of relative stability for the terminus of a retreating tide-water glacier.
\end{abstract}

RÉSUMÉ. La formation des seuils des fjords. La vitesse d'érosion du lit rocheux par un glacier est analysée pour les conditions d'un écoulement permanent radial, convergent et divergent, en supposant que la vitesse d'excavation du lit croît avec la vitesse de glissement, que le glissement suit une loi puissance conventionnelle et que la glace suit la loi de Glen. Tant que l'on limite convenablement le rapport entre le rayon de courbure du lit et l'épaisseur de glace le déviateur des contraintes calculé est négligeable devant le cisaillement à la base. Si la glace est assez épaisse l'écoulement radial divergent produit une vitesse d'érosion qui décroît vers l'aval. Ceci fournit une explication pour la formation de la plupart des seuils de fjords qui se situent aux points d'élargissement des vallées. Au contraire on

\section{INTRODUCTION}

Fjord thresholds or sills are shallow regions which commonly occupy the mouths of fjords where divergent flow takes place and interior regions where widening occurs. Occasionally, sills reside at very abrupt narrows which usually occur at interior regions. The correlation of sills with a widening channel has been noted by others, e.g. Holtedahl (1967); their correlation with abrupt rocky narrows is noted here as a result of an examination of charts of the fjords of the British Columbia coast. In anticipation of our analysis of this problem, we group all sills associated with divergent channels or wide regions under the name divergent sills (d.s.); those associated with narrows shall be referred to as convergent sills (c.s.)

Examples of d.s. have been illustrated by Holtedahl (1967) for Hardangerfjord, Norway, and its tributary fjords. The divergent flow associated with the mouth sill of Insugsuin Fjord, Baffin Island, has been illustrated clearly by Løken and Hodgson (1971). Picard (1956, 1963) showed prévoit des vitesses croissantes d'érosion dans les parties étroites ce qui peut epliquer la présence d'auges profondes dans les rétrécissements. On démontre que la présence de seuils prononcés dans les étroits peut être expliquée par une faible excavabilité ou une rugosité localement élevée réduisant la vitesse de glissement. L'origine des argiles à blocaux recouvrant les seuils s'explique comme une conséquence naturelle du fait que le seuil est une position de stabilité relative pour la langue terminale d'un glacier à front marin en décrue.

Zusammenfassung. Die Bildung von Fjord-Schwellen. Unter der Annahme eines konstanten radialen kon- und divergenten Eisflusses, einer mit zunehmender Gleitgeschwindigkeit wachsenden Schuttausbruchsrate und eines konventionellen Potenzgesetzes für das Gleiten wird die Rate der glazialen Erosion am Felsbett analysiert. Das Eis wird dabei als nicht-lineares Glen'sches Material betrachtet. Ablenkende Spannungen werden berechnet, doch erweisen sie sich gegenüber der Scherspannung am Untergrund als vernachlässigbar, sofern über das Verhältnis zwischen dem Krümmungsradius des Bettes und der Eisdicke vernünftige Einschränkungen getroffen werden. Wenn das Eis dick genug ist, führt radialer divergenter Fluss zu Erosionsraten, die gletscherabwărts abnehmen. Dieses Ergebnis liefert eine Erklärung für die Bildung der grössten Klasse von FjordSchwellen, die an Talöffnungen auftreten. Im Gegensatz dazu lassen sich verstärkte Erosionsraten an Engstellen erwarten, woraus das Auftreten tiefer Tröge an allmählichen Verengungen $\mathrm{zu}$ erklăren ist. Es wird dargelegt, dass sich ausgeprăgte Schwellen an schroffen Verengungen durch geringe Brüchigkeit oder lokale hohe Rauhigkeit, welche die Gleitgeschwindigkeit verringert, erklären lassen. Die Herkunft von Geschiebemänteln über den Schwellen ist als natürliche Folge davon zu verstehen, dass eine Schwelle für die Zunge eines zurückgehenden Gletschers am Gezeitenmeer eine Position relativer Stabilităt darstellt.

the longitudinal sections of the major fjords of the British Columbia mainland and Vancouver Island. (Unfortunately, longitudinal sections alone are not sufficient to distinguish between d.s. and c.s.; however, Picard's results contain a useful compendium of fjord sills.) St. John (unpublished) presented seismic profiles of a particular fjord, Howe Sound, British Columbia, which includes longitudinal profiles of three d.s. Seismic data are particularly useful because sediment thicknesses are revealed. In the case of Howe Sound, the thicknesses vary from less than $30 \mathrm{~m}$ over sills to greater than $900 \mathrm{~m}$ in troughs.

Fjords are characteristically of fairly uniform width. Local wide or narrow regions are usually not prominent. Exceptions to the rule are prominent mouth widenings which are common, and major broad interior sounds and abrupt narrows, which are uncommon. If no interior sills occur, generally, fjord depths increase towards the mouth up to the mouth sill. Exceptions exist such as in Burke and Work Channels, and Loughborough Inlet in British Columbia, where a gradual down-stream narrowing of these 
channels is associated with gradual shoaling up to a hanging mouth.

Mouth sills are typically very long - many times the average fjord width. Most have an undulating appearance along their length rather than the classical half sine-wave shape. Interior d.s. at wide regions are similar in appearance to mouth d.s. but usually much shorter. The presence of interior d.s. is usually masked by deep sediment. Interior c.s., though rare, are generally very prominent and have rocky bottoms.

Another characteristic of fjord bottoms is that relatively deep regions or trenches occur at gradual narrows. Although trenches are usually hidden by sediment, they can readily be seen in nautical charts of Dean Channel, British Columbia, in Gardner Canal (profile 24; Pickard, 1956) and by comparing the various seismic profiles of Howe Sound (St. John, unpublished) and of Jervis Inlet (Macdonald and Murray, 1973). We emphasize that c.s. occur at very short and very narrow regions, whereas trenches are associated with much less extreme configurations.

St. John's seismic profiles indicate a thick layer of till over d.s. However, rocky sill cores, comprising more than half the sill heights, are also indicated. Unless otherwise noted, we will concern ourselves only with the morphology of the rocky part of sills.

It is assumed here that fjords are the product of glacier erosion," which modifies a pre-existing topography which, in turn, dictates such things as the location of the fjord as well as the location of tributary fjords, sounds, and narrows. It follows from this assumption that sills result from a local reduction in glacial erosion. It remains to explain the origin of this reduced erosion.

No attempt has previously been made to apply the principles of abrasion or erosion theory to explain the morphology of sills, although Crary (1966) considered abrasion qualitatively. Crary analyzed a particular case, the ongoing formation of a fjord in Skelton Inlet, Antarctica, by a partially floating glacier. We believe that the Skelton Inlet situation does not apply to the formation of smaller fjords in more temperate climates. While it may be that very large floating glacier tongues are stable for long time periods, it has repeatedly been observed that medium-sized to small temperate floating tongues disintegrate rapidly. This observation leads us to consider only fully grounded glaciers. We shall later make separate consideration of erosion by three scales of glaciation: scale $\mathbf{S}-$ at the limit of minor glaciation where a fully grounded glacier has its calving terminus inside the fjord; scale $\mathbf{M}$ - at a larger scale of glaciation where the entire length of the fjord is glaciated but there is no large over-riding ice sheet; scale $\mathrm{L}$ - at the limit of major glaciation where the entire fjord system is covered by an ice sheet. (During the last major glaciation in British Columbia the ice-sheet thickness over the fjord region varied from $2 / 3$ to $2 \mathrm{~km}$ and exceeded $1 \mathrm{~km}$ over most of the region (Falconer, 1958).) We shall examine the contributions of these three scales of glaciation to sill morphology.

Our erosion model follows that of Shoemaker (in press); we assume that the processes are time-independent or timeaveraged. In addition, we neglect the abrasion rate compared to the quarrying rate so that erosion rate and quarrying rate are synonymous (Shoemaker, in press). However, we will show that the results would be unaffected by including abrasion, whatever its magnitude relative to quarrying.

While there is no established quarrying-rate law, it is reasonable that quarrying rate and sliding velocity $u_{\mathrm{b}}$ should be monotonically related. A law of the form

$$
\dot{q}=k_{\mathrm{q}} u_{\mathrm{b}}^{\gamma}
$$

was investigated by Shoemaker (in press). Here, the quarryability parameter $k_{\mathrm{q}}$ is a function of fracture properties and degree of jointing, and may also depend on other quarrying mechanisms unrelated to $u_{\mathrm{b}}$ such as basal effective pressure

*See Holtedahl (1967) for bibliography which supports the tectonic origin of fjords. and pressure fluctuations (Rothlisberger and Iken, 1981; Shoemaker, in press). Shoemaker (in press) argued that $y$ should be small, perhaps less than one. For convenience, we take $\gamma=1$; our results depend only on $\gamma$ being greater than zero. Thus, the erosion-rate law considered here is

$$
\dot{\epsilon}=k_{\mathrm{q}} u_{\mathrm{b}} .
$$

Note that the abrasion-rate contribution, which is neglected in Equation (1'), may be modeled by

$$
\dot{a}=k_{\mathrm{a}} c u_{\mathrm{b}}^{2} \text {. }
$$

This follows from Hallet $(1979,1981)$ and is consistent with Metcalf (1979). Here, $c \leqslant 1$ is a dimensionless basal debris concentration (Shoemaker, in press) and $k_{\mathrm{a}}$ is an attritivity coefficient. If $\dot{a}$ were included with $\dot{e}$ as an extra term in Equation (1'), $\dot{e}$ would still increase monotonically with $u_{\mathrm{b}}$ (which is all that we require). However, the inclusion of $\dot{a}$ would complicate the calculation of $\dot{e}$, because coefficients $c, k_{\mathrm{q}}$, and $k_{\mathrm{a}}$ are unknown.

The analysis will consider the effect of channel widening and narrowing on sliding velocity (or erosion rate). Channel widening (narrowing) will be idealized by considering radial divergent (convergent) flow. We will show that, in general, divergent flow results in a reduced sliding velocity and, hence, reduced erosion rate assuming a uniform $k_{\mathrm{q}}$ in Equation (1'). When integrated over time, this results in the formation of a d.s. The opposite effect occurs in convergent flow. The value of $\gamma$ in Equation (1) will not affect our conclusions, which rely solely on the qualitative relationships just described.

\section{ANALYSIS OF DIVERGENT AND CONVERGENT FLOW}

Figure 1 shows the notation, coordinate system, and sign conventions for a radial divergent flow with $r$ measured from the centre of curvature of a radial channel segment which begins at $r_{\mathrm{i}}$. It is assumed that up-stream of $r_{i}$ the channel width is constant. Zero accumulation is assumed over the (short) region of interest. (Calculations show that constant accumulation values do not affect the conclusions. A positive accumulation, for example, would produce an extensional flow, which would result in velocity and abrasion rates increasing down-stream. This effect, however, for reasonable accumulation rates, is only of secondary importance. The property, noted earlier, that interior fjord basins generally deepen down-stream indicates

(a)
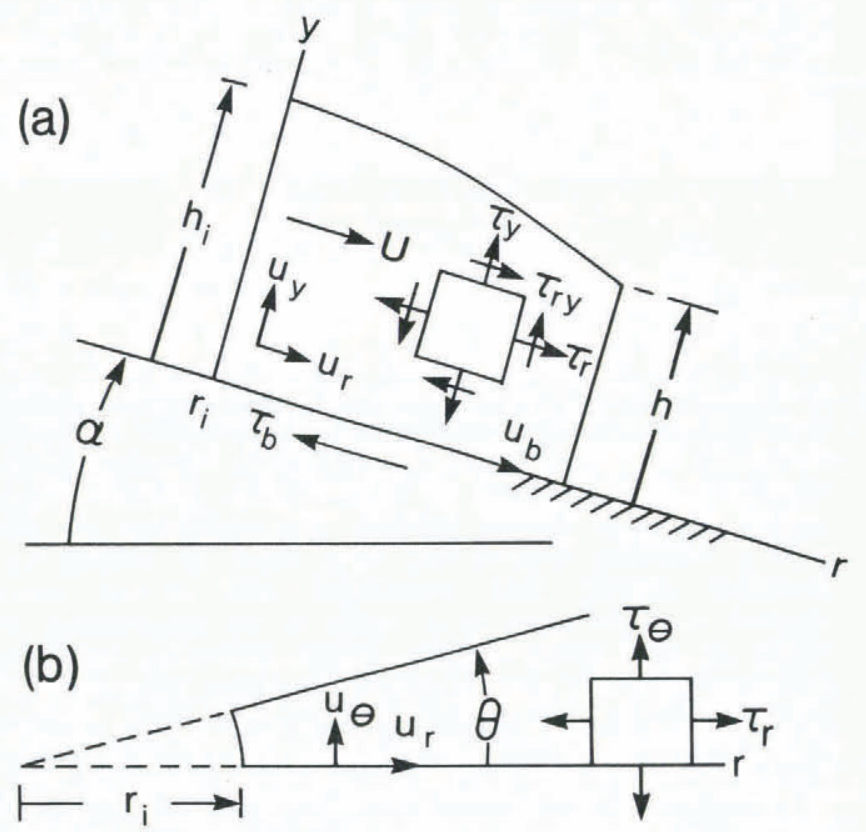

Fig. 1. Coordinate system, notation, and sign conventions for the divergent flow case: (a) side view, (b) plan view. 
that a major part of erosion takes place under conditions of positive accumulation.)

For this geometry, up-stream of section $r_{\mathrm{i}}$ basal velocity $u_{\mathrm{b}}$ and erosion rates increase very slowly in the down-stream direction. Therefore, we need only be concerned with $u_{\mathrm{b}}$ in the region of divergent flow, noting that the radial flow channel segment will be truncated at some point and can be assumed to issue into another constant-width channel where, again, $u_{\mathrm{b}}$ increases slowly down-stream.

The development here follows closely that of Shoemaker and Morland (1984) (SM), with two changes. First, the earlier plane-flow model is adapted to radial flow. Secondly, in accordance with the pseudohydrostatic (P-H) approximation discussed there, we tacitly assume that $\tau_{b}{ }^{2} \gg \tau_{\theta}^{2}$, $\tau_{\mathrm{b}}{ }^{2} \gg \tau_{r}{ }^{2}$ where $\tau_{\mathrm{b}}, \tau_{\theta}, \tau_{r}$ are the basal shear stress, transverse, and radial normal deviatoric stresses, respectively (Fig. 1). The inequalities must be verified a posteriori.

We need only consider the situation on the center line. There, by symmetry, $\dot{e}_{r \theta}=\dot{e}_{\mu \theta}=\partial u_{r} / \partial \theta=0$. As in the SM model, we assume $\left|\partial u_{y} / \partial r\right| \ll\left|\partial u_{r} / \partial y\right|$. From this point only the radial component of velocity enters into the formulation. Using the usual value of $n=3$ in Glen's flow law, the equations involving only $u_{r}$ reduce in their $\mathrm{P}-\mathrm{H}$ approximation to

$$
\begin{aligned}
& \dot{e}_{r}=\partial u / \partial r=A \tau_{r y}^{2} \tau_{r}, \\
& \dot{e}_{\theta}=u / r=A \tau_{r y}^{2} \tau_{\theta}, \\
& \dot{e}_{r y}=\frac{1}{2} \frac{\partial u}{\partial y}=A \tau_{r y}^{3}
\end{aligned}
$$

where $u \equiv u_{r}$. The SM model enables us to simplify the formulation by replacing variables $u(r, y), \tau_{r y}(r, y)$, and $\tau_{r}(r, y)$ by average velocity $U(r)$, basal shear stress $\tau_{b}(r)$, and average deviatoric stress $t_{r}(r)$, respectively. Variable $\tau_{\theta}$ will not appear explicitly.

As in SM, an average velocity (through the glacier thickness) is defined by

$$
U(r)=\frac{1}{h} \int_{0}^{h} u(r, \epsilon) \mathrm{d} \epsilon
$$

and a linear distribution of shear stress assumed

$$
\tau_{r y}(r, y)=\tau_{\mathrm{b}}(r)(1-y / h) .
$$

From Equation (6) an average longitudinal velocity is described by

$$
U(r)=u_{\mathrm{b}}(r)+\frac{1}{h} \int_{0}^{h} \oint_{0}^{\epsilon} \frac{\partial u}{\partial \eta}(r, \eta) \mathrm{d} \eta \mathrm{d} \epsilon
$$

where $u_{\mathrm{b}}$ is the sliding velocity.

By utilizing Equations (5) and (7) and evaluating the integral in Equation (8), we obtain

$$
U=u_{\mathrm{b}}+\frac{2}{5} A h \tau_{\mathrm{b}}^{3}
$$

which represents a flow equation.

A second flow equation may be derived by differentiating Equation (6) and using Equations (7) and (3) to evaluate the resulting integral. In this development we assume that $\tau_{r}$ is constant in $y$. (See SM for a discussion of this assumption.) With $t_{r}$ referring to this average deviatoric stress, the second flow equation is

$$
\frac{\mathrm{d} U}{\mathrm{~d} r}=\frac{\mathrm{d} h / \mathrm{d} r}{h}(u(r, h)-U)+\frac{A t}{3} r^{\tau_{\mathrm{h}}^{2}} .
$$

The quantity $u(r, h)$ in Equation (9) may be expressed in terms of $u_{\mathrm{b}}, h$, and $\tau_{\mathrm{b}}$ by a process similar to that used in obtaining Equation ( $\left.8^{\prime}\right)$. Thus,

$$
u(r, h)=u_{\mathrm{b}}+\frac{A h \tau_{\mathrm{b}}^{2}}{2} .
$$

Note that the approximation involved in determining Equations (3), (4), and (5) implies that Equations (8'), (9), and (10) are subject to the inequalities

$$
\tau_{\mathrm{b}}^{2} \gg t_{\theta}^{2}, \quad \tau_{\mathrm{b}}^{2} \gg t_{r}^{2}
$$

which must be verified. Here $t_{\Theta}$, which does not appear explicitly in the formulation, is an average deviatoric stress defined in the same way as $t_{r}$.

Consideration of equilibrium (see SM for the development in plane flow) results in a single equation, identical in form to that of plane flow,

$$
\tau_{\mathrm{b}}=(\rho g \sin \alpha) \mathrm{h}-(\rho g \cos \alpha) h \mathrm{~d} h / \mathrm{d} r .
$$

The derivation of Equation (12) assumes inequalities (11) or, equivalently, that $\sigma_{y}=-(\rho g \cos \alpha)(h-y)$. It is also assumed in the derivation that flow is independent of $\theta$.

Nye (1965) considered the effect of side drag in longitudinal independent flow and found that this could be accounted for approximately by including a shape factor (constant) $f$ in the equilibrium equation. Thus,

$$
\tau_{\mathrm{b}}=(f \rho g \sin \alpha) h
$$

applies on the center line where $f$ is a function of the cross-section geometry. We shall assume that Equation (12) can be modified by a shape factor for the longitudinal dependent cased. This modification is inexact but should be qualitatively consistent. Then Equation (12) is replaced by

$$
\tau_{\mathrm{b}}=(f \rho g \sin \alpha) h-(f \rho g \cos \alpha) h \mathrm{~d} h / \mathrm{d} r
$$

where $f$ is now a function of $r$ since the valley profile changes with $r$. It will be shown that our results are not affected qualitatively by the inclusion of a shape factor.

A consideration of mass balance under the previous assumptions of constant-flow and zero accumulation results in

$$
\frac{\mathrm{d}}{\mathrm{d} r}(U h r)=0, \quad U h r=U_{\mathrm{i}} h_{\mathrm{i}} r_{\mathrm{i}}
$$

where subscript $\mathrm{i}$ refers to initial values.

Finally, we must include a sliding law. It can be shown that any law of the class which expresses $\tau_{b}$ as a monotone increasing function of $u_{\mathrm{b}}$ will result in solutions with similar qualitative features. For concreteness we choose the conventional sliding law

$$
\tau_{\mathrm{b}}=\lambda u_{\mathrm{b}}^{1 / m}
$$

where $\lambda$ is a function of bed roughness and will be treated analytically as a non-constant function. However, there is no $a$ priori reason why bed roughness should vary so that in application $\lambda$ will be taken constant. (Note that Hallet (1981) and Shoemaker (in press) include a debris-sliding term in a sliding law. The addition of such a term in Equation (15) will not affect the conclusions provided basal debris concentration is uniform.)

The solution of Equations ( $\left.8^{\prime}\right),(9),\left(12^{\prime}\right),(14)$, and (15), along with Equation (10), in variables $U, u_{\mathrm{b}}, \tau_{\mathrm{b}}, h$, and $t_{r}$ will now be considered. Note that $t_{r}$ appears only in Equation (9) and our only interest in this quantity is to verify inequality (11). The variable $t_{\theta}$ does not appear in the formulation; it can be shown, using Equation (4) with $\tau_{\Theta}$ constant in $y$, that $\left|t_{\Theta} / \tau_{\mathrm{b}}\right| \ll 1$ provided that $r / h>5$.

It is convenient to introduce the following dimensionless dependent variables

$$
H=h / h_{\mathrm{i}}, \quad T_{\mathrm{b}}=\tau_{\mathrm{b}} / \tau_{\mathrm{bi}}, \quad T_{r}=\tau_{r} / \tau_{\mathrm{bi}}
$$


where subscripted $\mathrm{i}$ quantities refer to initial values at $r_{\mathrm{i}}$ (Fig. 1), along with the independent variable

$$
\xi=R / R_{\mathrm{i}}
$$

where $R=r / h_{\mathrm{i}}$. Also, we introduce a parameter

$$
q=\rho g h_{\mathrm{i}} \cos \alpha / \tau_{\mathrm{bi}},
$$

the ratio of overburden pressure to basal shear stress at $r=r_{\mathrm{i}}$.

Variables $U$ and $u_{\mathrm{b}}$ may easily be eliminated from the system. In order to simplify the resulting algebra we take $m=3$ in Equation (15) insted of the customary $m=2$. Because bed slopes are usually very small for fjord valleys we set $\alpha=0$. The resulting dimensionless system is
Figure 2. The convergent channel shape function $f(\xi)=1-\exp (-0.52 \xi)$ was chosen so as to fit Nye's results for parabolic cross-sections on the interval $0<w<2$ where $w$ is the ratio of half width to ice depth in the channel. Since average $w$ values are around $w=2$, this choice of shape function is appropriate to convergence from average-shaped to very narrow channels. The divergent channel shape function

$$
f(\xi)=1-0.65 \exp (-0.3 \xi)
$$

was chosen to fit Nye's results on the inverval $2<w<4$ and is therefore appropriate to divergence from a channel of average shape to a broad channel.

Figure 2 shows that divergent flow produces a sill

$$
\begin{gathered}
\frac{\mathrm{d} H}{\mathrm{~d} \xi}= \pm R_{\mathrm{i}}\left[\frac{U_{\mathrm{i}} / u_{\mathrm{bi}}}{\left[\frac{\lambda_{\mathrm{i}}}{\lambda}\right]^{3} H^{4}+\left[\frac{U_{\mathrm{i}}}{u_{\mathrm{bi}}}-1\right] H^{5}}\right]^{1 / 3} \frac{1}{q f(\xi) \xi^{1 / 3}}, \\
T_{\mathrm{b}}=\left[\frac{U_{\mathrm{i}} / u_{\mathrm{bi}}}{\left[\frac{\lambda_{\mathrm{i}}}{\lambda}\right]^{3}+\left[\frac{U_{\mathrm{i}}}{u_{\mathrm{bi}}}-1\right] H^{2}}\right]^{1 / 3} \cdot \frac{1}{\xi^{1 / 3}}, \\
\left.T_{r}=\mp \frac{3}{10} \frac{T_{\mathrm{b}}}{R_{\mathrm{i}}} \frac{\mathrm{d} H}{\mathrm{~d} \xi}-\frac{6}{5 R_{\mathrm{i}}}\left[\left[\frac{\lambda_{\mathrm{i}}}{\lambda}\right]^{3} \frac{1}{\left[\frac{U_{\mathrm{i}}}{u_{\mathrm{bi}}}-1\right.}\right]+H\left(\frac{1}{\xi}+\frac{1}{H} \frac{\mathrm{d} H}{\mathrm{~d} \xi}\right] T_{\mathrm{b}}\right] .
\end{gathered}
$$

Here, the upper signs correspond to divergent flow of Figure 1. For future consideration, the lower signs correspond to convergent radial flow where the coordinates $r$ and $\xi$ point up-stream with $U, u_{\mathrm{b}}$, and $\tau_{\mathrm{b}}$ adhering to the sign conventions of Figure 1. An additional parameter $U_{\mathrm{i}} / u_{\mathrm{bi}}$, whose physical meaning is clear has emerged.

\section{DIVERGENT AND CONVERGENT FLOW NUMERICAL \\ RESULTS}

Figure 2 illustrates typical results for divergent and convergent flow in very long channels where $\alpha=0$, $\lambda_{\mathrm{i}} / \lambda=1$ (constant roughness), $U_{\mathrm{i}} / U_{\mathrm{bi}}=6$, and $q=75$. (From Equation (18), with $\alpha=0, q=75$ corresponds to a glacier $420 \mathrm{~m}$ thick with basal shear stress of 0.4 bar.) The value $R_{\mathrm{j}}=3$ is sufficiently small that the restrictions $T_{r}^{2} \ll T_{\mathrm{b}}^{2}$ and $T_{\theta}^{2} \ll T_{\mathrm{b}}^{2}$ are violated in a small neighbourhood of $\xi=1$. Curves with $R_{\mathrm{j}}=5$, for example, satisfy the inequalities uniformly and differ little from Figure 2. (The restrictions we have imposed throughout are that $\left|T_{\Theta}^{2} / T_{\mathrm{b}}^{2}\right|<0.09, \quad\left|T_{r}^{2} / T_{\mathrm{b}}^{2}\right|<0.09$. These restrictions ensure agreement to two places between the present model, which neglects deviatoric stresses, and a radial flow model analogous to SM.)

From previous assumptions, the erosion rate $\dot{e}$ is proportional to $u_{\mathrm{b}}$ from Equation (1'). Assuming $u_{\mathrm{b}}$ constant over time, the initially horizontal center-line profile is eroded to the dimensionless profile $u_{\mathrm{b}} / u_{\mathrm{bi}}$. For convenience, an additive constant is included so that the graphed profiles $\left(1-u_{\mathrm{b}} / u_{\mathrm{bi}}\right)$ pass through the point $(1,0)$.

In addition, Nye shape functions were used to obtain

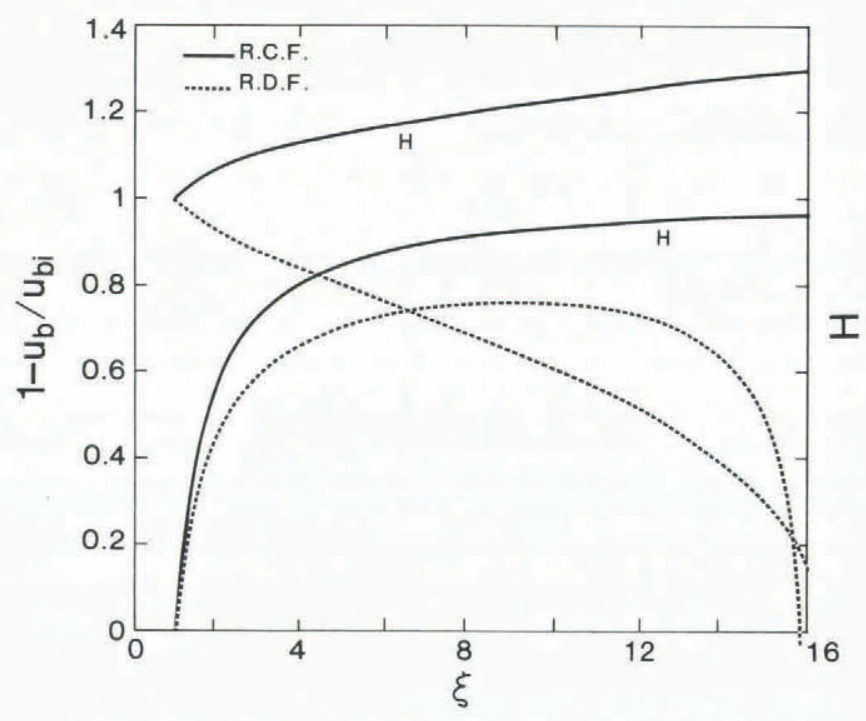

Fig. 2. $H$ and dimensionless center-line bed profile $\left(1-u_{b} / u_{b i}\right)$ versus $\xi$ for a typical case with $R_{i}=3$, $U_{i} / u_{b i}=6, q=75$. Radial convergent flow (R.C.F.) with $\xi$ measured up-stream from a very narrow channel with $f(\xi)=1-\exp (-0.52 \xi)$ and radial divergent flow (R.D.F.) with $\xi$ measured down-stream from a channel of average width-depth ratio and $f(\xi)=1-0.65$ exp $(-40.3 \xi)$. 
whereas convergent flow produces a bed which drops downstream. If convergent flow is followed by divergent flow, a trench is produced at the junction. These conclusions, however, are valid only for very long channels. Divergent fjord channels in British Columbia rarely exceed $15 \mathrm{~km}$ in length at mouths and this number would be reduced to $5 \mathrm{~km}$, or less, for interior divergent or convergent channels. At very abrupt rocky narrows the number would be $1 \mathrm{~km}$, or less. If, for example, we take $r_{\mathrm{i}}$ (Fig. 1) to be $15 \mathrm{~km}$ and $h_{\mathrm{i}}=1 \mathrm{~km}$, then $R_{\mathrm{i}}=15$ and a $15 \mathrm{~km}$ length channel translates into a range $1<\xi<2$. However, $R_{\mathrm{i}}=15$ does not correspond to initial point $\xi_{\mathrm{i}}=1$ in Figure 2 but rather to $\xi_{\mathrm{i}}=5$ (since Figure 2 is based on $R_{\mathrm{i}}=3$, instead of 15). For this example, the range in Figure 2 would be $5<\xi<10$. Furthermore, if initial points other than $\xi_{\mathrm{i}}=1$ are chosen in Figure 2, the initial values $q$ and $U_{\mathrm{i}} / u_{\mathrm{bi}}$ would be affected. Consequently, we cannot conveniently use Figure 2 as a master curve to illustrate results for channels with different values of $R_{\mathrm{i}}, q$, and $U_{\mathrm{i}} / u_{\mathrm{bi}}$. Put otherwise, flow in a divergent or convergent channel of typical length would result in a curve similar to, but not identical to, a small arc of the appropriate curve of Figure 2 .

We cannot immediately conclude that divergent flow in a channel of finite length produces a sill. This is because the divergent flow profile in Figure 2 rises and then falls. For example, the $\xi$ range for an actual finite-length divergent fjord channel might correspond to the dropping profile part of Figure 2. We must determine ranges of $\xi$ for actual cases.

There is a ready explanation for the qualitative character of Figure 2. First, it is apparent from Equation (20) that for fixed $H$ the geometric effect of channel widening (which enters through continuity), Equation (14), produces a decrease in $T_{\mathrm{b}}$ and $u_{\mathrm{b}}$ for increasing $\xi$. Secondly, from Equation (19), increasing $\xi$ produces a decrease in $H$. (This effect also occurs in plane flow but the decrease is less rapid.) This decrease in $H$, or increase in surface gradient, increases $T_{\mathrm{b}}$ and $u_{\mathrm{b}}$ through Equation (20). For small $\xi$, the first effect is dominant but as $\xi$ increases the second effect becomes dominant. On the other hand, in convergent flow both $H$ and $\xi$ increase in the up-stream direction and it is apparent from Equation (20) that $T_{\mathrm{b}}$ and $u_{\mathrm{b}}$ decrease monotonically.

Before investigating some typical cases, we consider the qualitative effects of changes in the parameters $R_{\mathrm{i}}, q$, and $U_{\mathrm{i}} / u_{\mathrm{bi}}$ on curves similar to Figure 2 . The effects of decreasing $R_{\mathrm{i}}$ have already been discussed. First, the initial point moves to the left on Figure 2. Secondly, as $R_{\mathrm{i}}$ moves to the left, eventually the restriction $T_{r}^{2} \ll T_{\mathrm{b}}^{2}$ will be violated. The effect of variation in $U_{\mathrm{i}} / u_{\mathrm{bi}}$ is small and is not tabulated here.

Table I shows the effect of increasing $q$ in Equation (18) on the following divergent-flow characteristics: the location of the initial point $\xi_{\mathrm{i}}$ whether to the left, $\mathrm{L}$, or right, $R$, of the top of the sill of Figure 2; the initial value $\left|T_{r}\right|_{j}$; the location $\xi^{*}$ of the top of the sill if it was encountered due to high $\left|T_{r} / T_{\mathrm{b}}\right|$ values, if those occurred. In all cases, runs were to $R / R_{\mathrm{i}}=12$ unless otherwise terminated; this is indicated in the $\xi$ column. Note that the ratio $\left|T_{r} / T_{\mathrm{b}}\right|$ first decreases and then increases; therefore the magnitude of $\left|T_{r}\right|_{\dot{i}}$ is an important measure in satisfying the restriction $\left|T_{r} / T_{\mathrm{b}}\right|<0.3$. The ratio becomes very large near the terminus, a situation which occurs only in scale $\mathrm{S}$ glaciation.

We deduce from Table I that an increase in $q$ appears to produce the same qualitative effect as a decrease in $R_{\mathrm{i}}$. To understand this, consider the situation where for a given divergent channel, and hence fixed initial radius of curvature $r_{i}$, the initial glacier thickness $h_{i}$ is varied. Since $q=\rho g h_{\mathrm{i}} / \tau_{\mathrm{bi}}$ if $\tau_{\mathrm{bi}}$ is kept constant (which is not entirely realistic) $q$ increases linearly with $h_{\mathrm{i}}$. Since $R_{\mathrm{i}}=r_{\mathrm{i}} / h_{\mathrm{i}}, R_{\mathrm{i}}$ decreases with increasing $h_{\mathrm{i}}$. Consequently, increasing $q$ or decreasing $R_{\mathrm{i}}$ corresponds to an increase in the physical variable $h_{\mathrm{i}}$.

These remarks suggest an examination of the effect of a change in $h_{\mathrm{j}}$ on the erosion characteristics of divergent flow. This is of fundamental importance since we are interested in the effects of erosion throughout the spectrum of glaciation. Table II presents such results where the $\hat{\xi}$ values,
TABLE I. EFFECTS OF $q$ ON QUALITATIVE SILL FEATURES

$\begin{array}{llccr}q & \xi_{\mathrm{i}} & \left|T_{r}\right|_{\mathrm{i}} & \xi^{*} & \hat{\xi} \\ 10 & \mathrm{R} & 0.15 & - & 1.3 \\ 20 & \mathrm{~L} & 0.13 & 1.1 & 1.8 \\ 30 & \mathrm{~L} & 0.22 & 1.4 & 2.4 \\ 40 & \mathrm{~L} & 0.23 & 1.8 & 2.9 \\ 75 & \mathrm{~L} & 0.29 & 3.8 & 6.2 \\ 150 & \mathrm{~L} & 0.32^{\dagger} & 10.37 & 12 \\ 600 & \mathrm{~L} & 0.34^{\dagger} & - & 12\end{array}$

All cases for $R_{\mathrm{i}}=6, U_{\mathrm{i}} / u_{\mathrm{bi}}=2, \alpha=0$, using shape function (22).

${ }^{+}$Restriction $\left|T_{r} / T_{\mathrm{b}}\right|<0.3$ is violated in the neighbourhood of the initial point for two cases; the restriction is satisfied elsewhere.

TABLE II. EFFECT ON QUALITATIVE SILL CHARACTERISTICS RESULTING FROM DIVERGENT FLOW OF AN INCREASE IN $q$, OR INCREASE IN $h_{\mathrm{i}}$, WITH $\tau_{\text {bi }}$ FIXED

$\begin{array}{rccccc}R_{\mathrm{i}} & q & \xi_{\mathrm{i}} & \left|T_{r}\right|_{\mathrm{i}} & \xi^{*} & \hat{\xi} \\ 25 & 30 & \mathrm{R} & 0.083 & - & 1.3 \\ 20 & 37.5 & \mathrm{R} & 0.022 & - & 1.4 \\ 15 & 50 & \mathrm{~L} & 0.054 & 1.1 & 1.86 \\ 10 & 75 & \mathrm{~L} & 0.14 & 2.1 & 3.4 \\ 5 & 150 & \mathrm{~L} & 0.39^{\dagger} & 14.2 & 21\end{array}$

All cases for $U_{\mathrm{i}} / u_{\mathrm{bi}}=2, \alpha=0$, using the shape function (22).

${ }^{+}$The restriction $\left|T_{r} / T_{\mathrm{b}}\right|<0.3$ is violated initially for one case.

in all cases, correspond to a cut-off due to the restriction $\left|T_{r} / T_{\mathrm{b}}\right|<0.3$. As noted, as $q$ (or $h$ ) varies $R_{\mathrm{i}}$ varies inversely.

Since, for $q \leqslant 37.5, \xi_{\mathrm{i}}$ is to the right of the maximum on the master curve in Figure 2 it is clear that for divergent flow small-scale glaciation erodes a base which slopes down-stream - a "falling bed". As glacier thicknesses increase and $\xi_{i}$ moves to the left of the maximum in Figure 2, classical sills are produced where the bottom rises and then falls in the down-stream direction over a typical channel length of perhaps $10 \mathrm{~km}$. If $q$ is sufficiently large, because the range of $\xi$ is limited to about order three, the glacier erodes a base which rises down-stream to the end of the diverging channel - a rising bed (which can still be considered a sill). The following paragraphs will consider typical $q$ values for the three scales of glaciation. With this information, Table II can be related to realistic cases.

We now investigate six typical cases: scale $\mathbf{S}, \mathbf{M}$, and $\mathbf{L}$ glaciation for large and small fjords. For all cases the shape function is of the form in Equation (22). In the first column of Table III, capitals refer to the glaciation scale and subscripts $l$ and $s$ refer to large and small fjords, respectively. The values of $U_{\mathrm{i}} / u_{\mathrm{bj}}$ are determined by assuming arbitrarily one of the values in the column of 
TABLE III. ASSUMED $h_{\mathrm{i}}, r_{\mathrm{i}}$, AND $\tau_{\mathrm{bi}}$ VALUES, AND CALCULATED $U_{\mathrm{i}} / u_{\mathrm{bi}}$ AND $q$ VALUES FOR SIX COMBINATIONS OF THREE GLACIATION SCALES AND TWO DIVERGENT CHANNEL LENGTHS

$\begin{array}{llrrrrr} & \begin{array}{l}h_{\mathrm{i}} \\ \mathrm{km}\end{array} & \begin{array}{c}r_{\mathrm{i}} \\ \mathrm{km}\end{array} & R_{\mathrm{i}} & U_{\mathrm{i}} / u_{\mathrm{bi}} & \begin{array}{l}\tau_{\mathrm{bi}} \\ \mathrm{bar}\end{array} & q \\ \mathrm{~S}_{\ell} & 0.5 & 7.5 & 15 & 2.25 & 0.5 & 100 \\ \mathrm{M}_{\ell} & 1 & 7.5 & 7.5 & 3.5 & 0.33 & 300 \\ \mathrm{~L}_{\ell} & 1.5 & 7.5 & 5 & 4.75 & 0.25 & 600 \\ \mathrm{~S}_{\mathrm{s}} & 0.3 & 6 & 20 & 1.75 & 1.0 & 30 \\ \mathrm{M}_{\mathrm{S}} & 0.75 & 6 & 8 & 2.88 & 0.75 & 100 \\ \mathrm{~L}_{\mathrm{s}} & 1.5 & 6 & 4 & 4.75 & 0.25 & 600\end{array}$

values. The remaining values are then determined from

$$
U_{\mathrm{i}} / u_{\mathrm{bi}}=1+\frac{2}{5} A h_{\mathrm{i}} \lambda^{3}
$$

which follows from Equation (15), with $m=3$, and Equation ( $\left.8^{\prime}\right)$; here, $A$ and $\lambda$ are fixed so that a uniform temperature and sliding law have been assumed. The particular, somewhat subjectively chosen, values of $\tau_{b i}$ are meant to convey the qualitative tendency that an increase in ice thickness corresponds to a decrease in surface, gradient. (In the $\mathrm{P}-\mathrm{H}$ model the initial surface slope is $h_{\mathrm{i}}^{\prime}=1 / q$.) The value $r_{i}=6 \mathrm{~km}$ for the small fjord should be smaller but was chosen to be as small as possible without producing more than a local violation of the inequality restrictions on $T_{\Theta}$ and $T_{r}$.

Table II can now be interpreted in terms of realistic cases. It is clear that all three erosion cases emerging from Table II occur among the six cases of Table III: falling beds, classical sills, and rising beds.

Figure 3 graphs basal profiles in the form $\tau_{\mathrm{bi}}^{3}\left(1-u_{\mathrm{b}} / u_{\mathrm{bi}}\right)$ versus $\xi$ for the six cases of Table III where convergent flow on $3>\xi>1$ is followed by divergent flow on $1<\xi<5$. The section at $\xi=1$ corresponds to $w=2$ and shape function (22) is used. (The qualitative results are not affected by using a constant shape function.) In order to compare relative abrasion rates, the factor $\tau_{\mathrm{bi}}^{3}\left(\mathrm{bar}^{3}\right)$ is included in Figure 3. From Equations (1') and (15) with $m=3$, this scales all erosion rates to a

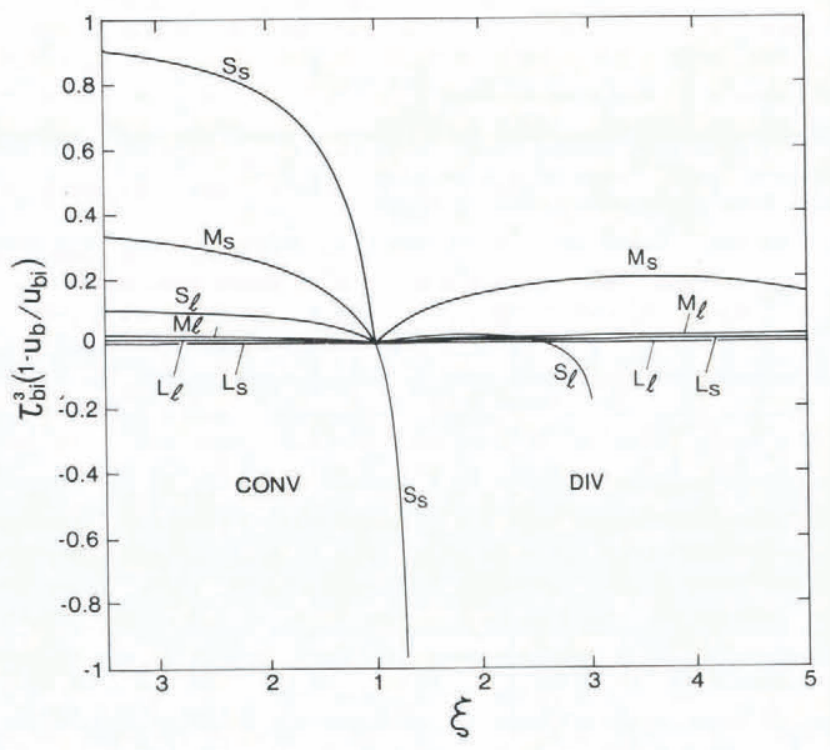

Fig. 3. Center-line profiles as measured by $\tau_{b i}^{3}\left(1-u_{b} / u_{b i}\right)$ versus $\xi$ for six prototype cases. Convergent flow on $3>\xi>1$ down to a narrows of average width-depth ratio is followed by divergent flow on $1<\xi<5$. common set of physical parameters such as quarryability and roughness; otherwise the curves can be interpreted in the same way as those of Figure 2.

If the maximum length of divergent channels for large fjords is set at $20 \mathrm{~km}$, this translates into the range $1<\xi<2.7$; similarly, a $15 \mathrm{~km}$ length small fjord channel translates into the range $1<\xi<1.67$. These ranges effectively truncate the graphs of Figure 3.

Because of the larger surface gradients, and hence larger sliding velocities, scale $\mathrm{S}$ glaciation produces the largest erosion rates. However, because large-scale glaciation can be assumed to be present for a longer time, we cannot conclude that the erosion by small-scale glaciation predominates in fjord formation. It must also be noted that $\lambda$ should actually decrease with glacier size. This is because water entrapment at the base of large glaciers leads to cavitation and fast sliding. Therefore, the erosion rates for the $S_{s}$ and, perhaps, $M_{s}$ cases should be decreased relative to the remaining cases.

For converging-diverging channels, Figure 3 offers the following conclusions regarding erosion. In cases $\mathrm{M}_{\ell}, \mathrm{L}_{\ell}$, and $\mathrm{L}_{\mathrm{S}}$ a $\mathrm{V}$-shaped center-line profile is produced. In cases $\mathrm{M}_{\mathrm{S}}$ and $\mathrm{S}_{\ell}$ a converging channel with a dropping bed is followed by a diverging channel with a classical sill. (The statement applies in general only if the graphs are continued to $\xi=5$.) Case $\mathrm{S}_{\mathrm{S}}$ produces only a dropping bed; truncation of the run at $\xi=1.3$ corresponds to extreme ice thinning and numerical instability.

Figure 3 can obviously be used to analyze the case of divergent flow followed by convergent flow. Instead of a $\mathrm{V}$-shaped profile, for example, an inverted V-shaped profile is produced.

Actual fjord geometries do not, of course, correspond to the idealization of pure radial flow in converging and diverging channels. In addition, there is never an abrupt change from convergence to divergence as considered here. Finally, the erosion pattern of a given fjord would vary as the scale of glaciation varies so that an integration process is involved in evaluating the effect of erosion of a given fjord over the entire history of glaciation. Within these restrictions many qualitative features of fjord abrasion can be inferred from the above results.

\section{THE ORIGIN AND DEVELOPMENT OF CONVERGENT} SILLS

It is clear that the formation of c.s. is not consistent with the previous analysis. Before advancing a scenario for the formation of c.s., we note some facts concerning three prominent narrows on the British Columbia mainland and offer an explanation of why their sills, once initiated by whatever process, have persisted to their present state and should continue to persist through future glaciations.

The three examples are Skookumchuck Narrows (S.N.), Tzoonie Narrows (T.N.), and Malibu Narrows (M.N.). As is evident from nautical charts, aerial photographs, and personal observations in the case of S.N. and T.N., all three have extremely rough stepped bottoms. All basal debris has been swept from S.N. and M.N. by strong tidal action. The basal debris situation is unknown at T.N. where tidal action is weak. At S.N. and T.N. one side of the narrows consists of very loose rock and there are active rock slides; the other side consists of sparsely jointed rock.

In all three cases rocky islets exist down-valley from the narrowest section which is, itself, down-valley from the region with the steepest valley sides. Average water depths in fathoms [ 1 fathom $=1.8 \mathrm{~m}$ ], with the first number applying just up-valley from the narrows, the second applying at the narrows, and the third down-valley from the narrows, are: S.N. 20-7-30, T.N: 33-6-21, M.N.: 27-4-26. In the case of S.N. the rock type is uniform in a long reach including the narrows (Bacon, 1957). This appears also to be the case for T.N. and M.N. as shown on geological maps.

The very rough stepped nature of these sills plus the presence of rocky islets in the narrows implies that a very high sliding resistance exists at present and should persist through future glaciation. (We note that rocky glacierformed steps are common and once created tend to persist.) 
Equation (15) predicts that at high roughness the sliding velocity can be greatly reduced. Thus, we conclude that these rough stepped narrows sills will tend to persist and develop, relative to the neighboring valley floor, through subsequent glaciation.

The explanation for the origin of c.s. is more speculative. A local reduction in quarryability is one possibility but can almost be ruled out in the case of S.N. and T.N., where the rock on one side is gravel and should quarry very easily.

Another, more likely, explanation is that the local nature of the bedrock jointing and bedding planes is such that quarrying produces a rough stepped bed only locally. This hypothesis cannot be easily checked for the c.s. considered here because in all cases bedrock outside the sill region is covered by thick sediment. A third explanation is that periodically a high local debris concentration is created by local slides. This causes increased sliding resistance, perhaps lodgement. (Lodgement is consistent with Hallet's (1981) model of debris-influenced sliding.) However, high basal debris concentration should not persist over time because fluvial flushing of debris by $\mathrm{R}-$ and $\mathrm{N}$-channels would soon sweep out the debris. Therefore, this explanation is doubtful.

\section{THE ORIGIN OF TILL OVERLYING DIVERGENT SILLS}

As previously noted, the rocky core of d.s. is covered by glacial till. The morphology of such a till moraine can be explained. During scale $S$ glaciation of a retreating tide-water glacier, the calving terminus would be relatively stable at a narrows or at a sill. To understand this, consider an empirical formula of Meier and others (1980). Thus, the long-term calving rate of grounded tide-water glaciers appears to follow

$$
Q_{\mathrm{c}}=C h_{\mathrm{w}} S
$$

where $Q_{\mathrm{c}}$ is the iceberg flux away from the terminus, $C$ a universal constant, $h_{\mathrm{w}}$ the water depth at the terminus, and $S$ the cross-sectional area at the terminus. Once a sill is formed, $h_{\mathrm{w}}$ for a valley will have a local minimum there. $S$ increases slowly and continuously through the divergent channel but the decrease in $h_{\mathrm{w}}$ at a sill will dominate the increase in $S$. Equation (24) thus predicts a local minimum in iceberg flux if the terminus is at a sill.

A glacier terminus retreats because the iceberg flux predicted by Equation (24) cannot be satisfied by the glacier flux if the terminus position is fixed. It is clear from the previous paragraph that a glacier terminus will be locally stable at a sill because the glacier flux is better able to supply the locally reduced iceberg-flux requirement.

A calving terminus deposits debris. Furthermore, a retreating terminus which remains at one position for a relatively long time period will generally leave a moraine in that position. This explains the correlation of moraines with d.s. (Note that the conditions for moraine development apply even more so at a c.s. where no till is evident in our three examples. However, as previously noted, tidal and subglacial stream action has removed all debris.)

\section{CONCLUSION}

We have shown that divergent sills can be a consequence of reduced abrasion and quarrying resulting from divergent flow under medium- to large-scale glaciation where uniform basal debris concentration is assumed. Similarly, the model predicts the observed deep troughs at minor narrows.

The undulating character of most d.s. can be explained as the integrated effect of different erosion-rate distributions resulting from the changing scale of glaciation. A variation in rock type and quarryability would also be a factor. The common occurrence of till covering d.s. is explained as resulting from the relatively long time that a retreating calving glacier terminus is situated at a (shallow) sill. A calving terminus is also stable at c.s. but it is common that debris is swept away by tidal action in this case.

Convergent sills are rare. Their occurrence is incompatible with the combined assumptions of uniform roughness and quarryability. The present rough stepped nature of the c.s. mentioned here suggests that localized high roughness has persisted through many glaciations.

\section{ACKNOWLEDGEMENTS}

This work was prompted by M. Roberts (Simon Fraser University Geography Department) asking what I thought of Crary's model of sill formation. I benefited by checking numerous points with B. Hallet and W. Mathews. M. Meier outlined in a pre-publication form the calving formula used here. The computations were performed by J. Shoemaker. The work was partially supported by an NSERC grant.

\section{REFERENCES}

Bacon, W.R. 1957. Geology of lower Jervis Inlet. British Columbia Department of Mines. Bulletin, No. 39.

Crary, A.P. 1966. Mechanism for fiord formation indicated by studies of an ice-covered inlet. Geological Society of America. Bulletin, Vol. 77, No. 9, p. 911-29.

Falconer, J., comp. 1958. Glacial map of Canada. Toronto, Geological Association of Canada. [Scale 1:3,801,600.]

Hallet, B. 1979. A theoretical model of glacial abrasion. Journal of Glaciology, Vol. 23, No. 89, p. 39-50.

Hallet, B. 1981. Glacial abrasion and sliding: their dependence on the debris concentration in basal ice. Annals of Glaciology, Vol. 2, p. 23-28.

Holtedahl, H. 1967. Notes on the formation of fjords and fjord-valleys. Geografiska Annaler, Vol. 49A, Nos. 2-4, p. 188-203.

Løken, O.H., and Hodgson, D.A. 1971. On the submarine geomorphology along the east coast of Baffin Island. Canadian Journal of Earth Sciences, Vol. 8, No. 2, p. $185-95$.

Macdonald, R.D., and Murray, J.W. 1973. Sedimentation and manganese concentration in a British Columbia fjord (Jervis Inlet). Geological Survey of Canada. Paper 73-23.

Meier, M.F., and others. 1980. Predicted timing of the disintegration of the lower reach of Columbia Glacier, Alaska, by M.F. Meier [and 7 others]. U.S. Geological Survey. Open File Report 80-582.

Metcalf, R.C. 1979. Energy dissipation during subglacial abrasion at Nisqually Glacier, Washington, U.S.A. Journal of Glaciology, Vol. 23, No. 89, p. 233-46.

Nye, J.F. 1965. The flow of a glacier in a channel of rectangular, elliptic or parabolic cross-section. Journal of Glaciology, Vol. 5, No. 41, p. 661-90.

Pickard, G.L. 1956. Physical features of British Columbia inlets. Transactions of the Royal Society of Canada, Vol. 50 , Ser. 3 , p. $47-58$

Pickard, G.L. 1963. Oceanographic characteristics of inlets of Vancouver Island, British Columbia. Journal of the Fisheries Research Board of Canada, Vol. 20, No. 5, p. 1109-44.

Röthlisberger, H., and Iken, A. 1981. Plucking as an effect of water-pressure variations at the glacier bed. Annals of Glaciology, Vol. 2, p. 57-62.

St. John, R.W. Unpublished. Interpretation of seismic profiles of Howe Sound. [B.Sc. thesis, University of British Columbia, 1972.]

Shoemaker, E.M. In press. Debris-influenced sliding laws and basal debris balance. Journal of Glaciology.

Shoemaker, E.M., and Morland, L.W. 1984. A glacier flow model incorporating deviatoric stresses. Journal of Glaciology, Vol. 30, No. 106, p. 334-40. 